Portland State University

PDXScholar

1975

\title{
An Exploratory Study of the Role of Research in Social Work at Portland State University
}

Jo Mackay Imeson

Portland State University

Audrey Englebardt Zalutsky

Portland State University

Follow this and additional works at: https://pdxscholar.library.pdx.edu/open_access_etds

Part of the Social Work Commons

Let us know how access to this document benefits you.

\section{Recommended Citation}

Imeson, Jo Mackay and Englebardt Zalutsky, Audrey, "An Exploratory Study of the Role of Research in Social Work at Portland State University" (1975). Dissertations and Theses. Paper 1896.

https://doi.org/10.15760/etd.1895

This Thesis is brought to you for free and open access. It has been accepted for inclusion in Dissertations and Theses by an authorized administrator of PDXScholar. Please contact us if we can make this document more accessible: pdxscholar@pdx.edu. 
AN EXPLORATORY STUDY OF THE ROLE OF RESEARCH IN SOCIAL WORK

$\mathrm{AT}$

PORTLAND STATE UNIVERSITY

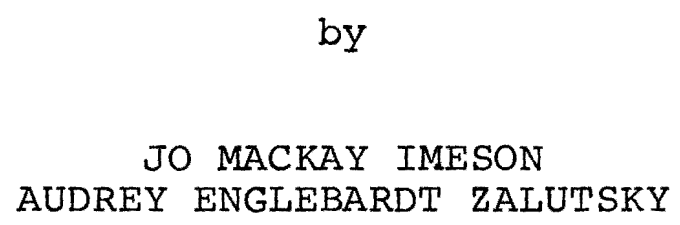

A research project submitted in partial fulfillment of the requirements for the degree of

MASTER OF SOCIAL WORK

Portland state University

1975 
TO THE OFFICE OF GRADUATE STUDIES:

The members of the Committee approve the research study of Jo Mackay Imeson and Audrey Englebardt Zalutsky presented May 23, 1975. 
ACKNOWLEDGMENT

We are pleased to acknowledge and to express our sincere gratitude to the following individuals who advised us as we proceeded on this project: Dr. Frank Miles, Professor and Research Coordinator, who read the results of our questionnaire and provided a comprehensive critical analysis of our research efforts and many helpful comments; Jack Finley, associate professor, who provided guidance with planning and encouragement to pursue this study; we extend our appreciation to Wayne Neuberger, Research Instructor, for his competent guidance.

We extend our special thanks to the following members of the Portland State School of Social Work community:

first year students 1973-1974

second year students 1973-1974

first year students 1974-1975

faculty and field supervisors

agency directors

We are especially indebted to Karen Goldmann whose expert organizational skills and typing helped to complete this study • 
I. INTRODUCTION $\ldots \ldots \ldots \ldots \ldots \ldots \ldots \ldots \ldots \ldots \ldots$

II. A REVIEW OF THE IITERATURE............. 4

III. PROGRAM COMPONENTS................. 17

IV. JUSTIFICATION FOR THE RESEARCH PROGRAM AT PSU..................... 25

V. METHODOLOGY..................... 27

VI. ANALYSIS AND EVALUÁTION OF THE QUESTIONNAIRES.................... 44

VII. CONCLUSIONS AND RECOMMENDATIONS.......... 55

VIII. A SELECTED BIBLIOGRAPHY.............. 66

APPENDIX A.......................... 69

APPENDIX B....................... 7 I 


\section{INTRODUCTION}

The purpose of this study was to explore and to evaluate the role of research in social work from the points of view of different populations affiliated with the Portland State University School of Social Work community. Students, faculty and field instructors, and agency directors were asked to express their subjective opinions in an effort to explore attitudes regarding the role of research in social work and to evaluate their estimate as to the value and position of the research component in the curriculum at Portland State University. The research program is intended to assist the student in becoming an effective professional person.

The authors became interested in the role of research in social work as a result of participation in a previous research project which raised a number of significant issues regarding the role of the research component in the social work curriculum and its value in social work practice. One of those issues is whether or not the social work profession would be seriously affected if only a few of its members are capable of. understanding research in social work, psychology, sociology, psychiatry, and in other helping professions. A second issue generated by the earlier study is whether or not current research education in the School of Social Work is transmitting sufficient knowledge of theory, of cognitive 
research skills, and of evaluation and utilization techniques to meet the needs of practicing social work professionals.

A third issue is related to the realization that in social agencies, evaluation research is an essential requirement of social work practice and administration in examining effectiveness of agency policies and programs. Funding sources increasingly require ongoing evaluative research to examine the effectiveness and costs of social programs. In our study, we are seeking to identify attitudes toward research in relation to these basic questions.

We are unaware of any previous research study designed to evaluate the research component for the purpose of exploring the role of research in social work at Portland state University. We are especially seeking both student and practitioner views of the importance of a research experience in social work education and practice.

Findings of this study should be of interest to faculty responsible for research in the Master of Social Work curriculum as well as to students in the school, to prospective students and to practitioners, in the social work field. The study also suggests other aspects of research in social work in need of examination.

In conclusion, we want to relate our findings to the basic questions of (1) why is research knowledge and experience necessary for social work students; (2) what educational and professional purposes are to be achieved; and (3) 
what is the most effective way to teach research knowledge and to provide research experience. 


\section{REVIEW OF THE LITERATURE \\ THE ROLE OF RESEARCH IN SOCIAL WORK EDUCATION AND PRACTICE}

I want only to point out that the genuine solution to dilemmas of society are to be found not by people who have opinions and not only by people who have marshalled facts. What is needed are people who, quite simply, know how to synthesize knowledge and find connections between distinctly related phenomena, who seek constantly to relate rather than to isolate experiences. "The Role of Men of the Mind in the World Today," The Nonconformers, Arthur Miller, N.Y., 1961.

\section{EVOLUTION OF RESEARCH IN BASIC} SOCIAI WORK CURRICULUM

A place for research in social work education appears to date back to the early 1900's in the history of one of the oldest institutions. In A History of the N.Y. School of Social Work (Meier 1954), there is a description of a course entitled "Social Research," the successor to "Statistics," a course which came into existence sometime after 1914. The purpose of the course was to examine the steps in social research which included planning the investigation, collecting the material, arranging it in correct and interesting form, and interpreting the results. Skills involved were the construction of schedules, tables and graphs, computation of percentages and averages, and preparation of an explanatory text. In 19.16-17, topics included in the research curriculum 
were race problems, poverty, disease and defects, and deIinquency. Research was not yet listed as one of the five separate areas of study in the curriculum of 1918-19. Five major vocational fields were listed: Community organization, Criminology, Public Health, Industry, and Family and Child Welfare.

In Social Work Education in the U.S. (Hollis and TayIor 1951), it was observed that schools of social work ad- * hered to no minimum curriculum in 1928. There was an exchange of views between schools; however, curriculum matters were not considered in a uniform way until a minimum recommended curriculum was adopted by the American Association of Schools of Social Work in 1931.

In 1944, it was recommended to and adopted by the American Association of Schools of Social Work that the generic program be revised to include social research among eight basic areas of social work content. The Association urged all member schools to make eight areas available, including social research, as constituting the generic foundation for all professional practice.

By 1949, professional research workers had organized a national association of persons engaged in social work research.

The literature relating to the importance of research in education indicates some conflicting points of view. Tufts (1923) comments that a minority of students will be 
research types while the majority will be practitioner, administrative or engineer types. We wonder whether this argument is valid now, what implications there are for present curriculum planning and whether current developments in social work education have made this observation obsolete.

A more optomistic frame of reference is stated in Tripodi (1974): he comments that the acquisition of knowledge that can be applied in professional practice is a key component in education for social work, recognizing that research knowledge is exceedingly significant for practice. In giving recognition to the importance of research knowledge, Tripodi does not make dichotomies among types of students who might benefit from incorporating research into the professional curriculum of social work schools. Rather, Tripodi recognizes the research knowledge from the social. and behavioral sciences has been incorporated successfully to a considerable degree in the professional curriculum of social work. However, he laments the fact that a lag between knowledge development and application is a serious obstacle to effective social work practice.

Schools of social work until recently have followed academic traditions in matters associated with the masters degree and research requirements. Students have met the routine standards, including individual thesis research, but more often than not have learned little that contributed to a vital research point of view or that developed effective 
consumers of research findings.

Despite encouraging signs, training in research either for consumer or for specialist remains a relatively undeveloped area of professional education. Hollis and Taylor (1956) commented that constant faculty attention and increased investments of time and money would be required in the future if social work research is to meet the challenges that lie ahead for rescuing the profession from overdependence on empirical practices.

A critical opinion regarding the teaching of research expresses another point of view; namely, that most schools of social work set course and thesis requirements as if all. students had elected to become research workers. What is needed instead is the capacity to read, interpret and use research findings, supporting the necessity for inculcating the research point of view into social work education.

In support of teaching the research component and point of view, a curriculum policy statement for degree programs in social work states that a concern for the development of new knowledge and the testing of generally accepted principles, formulations and hypotheses should be evident in the entire curriculum. The student should be encouraged to question constructively all aspects of the body of knowledge which is transmitted in education for social work practice. 
Hollis and Taylor (1951) state that a few schools of social work envisaged the importance of research from the beginning and provided the profession with a small corps of research workers. It was believed that social work had, for the most part, depended on other fields for its research personnel although there had been expectations and indications that other schools would be devising programs to alter the situation.

The educational programs and the field of practice began to take necessary steps to improve the situation sometime after it became apparent that there had been an inability of the profession to supply vital factual information on social work during and following world War II. when it became apparent that there was urgent need that carefully planned research be undertaken by workers adequately prepared for it.

The attitude developed that social work education be relevant and responsive to changing developments and demands of practice, so that feedback and information would be available to the schools of social work to enhance their awareness of the programs and problems of social work practice. This kind of cooperation has been accomplished by involving students, social work professionals, agency representatives and others in the planning and governance of the schools of social work. Openness in system has been the means to enable the schools of social work to keep up with currently needed changes in socialized society, recognizing that what is 
taught and how it is taught should be in a continual stage of development.

Historically, research was centered around acquiring new knowledge regarding the nature of growth, of health, and of disease for precipitating changes in social conditions by organizing community action.

There has been little involvement in conducting social research by social workers. In fact, social work functions with the lowest investment in research and development of any major enterprise in the United States, perhaps less than .003 percent of the sums being planned for research (Robert Morris 1966).

One cannot argue with the observation that the vast majority of social workers have not been trained to initiate and carry out research and that social work personnel engaged in research have been primarily those few persons with doctoral degrees who have received advance training in social research.

However, content analyses of social work periodicals in the 1950's and 1960's have revealed an increasing percentage of the articles are devoted to research and evaluation.

It is still apparent that many social research studies pertinent to social work have been conducted by professionals other than social workers, i.e. sociologists, psychologists, public health researchers, management analysts and others. 
In fact, it is recognized in the literature that much of the research related to social work has been conducted by social scientists with social work interests, rather than by practicing social workers.

Some authors point out that there is a conflict about social research and social work practice being seen as separate enterprises. Apparently, there are recognized conflicts between researchers and practitioners. These conflicts are blamed on two basic sources: perceived differences in objectives and the perceived threat of evaluation. Perhaps practitioners are typically concerned with immediate decisions in their practice, while researchers proceed cautiousIy and methodically in their work.

In some instances, research might be perceived as threatening if it has the function of evaluating practice, for it might lead to discussions that would affect the conduct and nature of the practice.

However, social workers need the self-awareness that comes from the objective study of themselves and their practice, thus leading one to question the need for any dichotomy or conflict to exist between research and practice (Paul, Schuman and Davis, Portland State University 1973).

In relation to accountability in practice, it has been recognized in the literature that social work as a profession is accountable for the work it does with and for its various constituencies, and specifically that social workers are 
accountable to their clients, community representatives, funding bodies, fellow professionals and the general public.

Accountability requires that practice must be open to the scrutiny of colleagues in order to get new perspectives and in order for errors to be corrected and brought to light. Furthermore, social work can only be accountable if it pays close attention to examining its activities in relation to effectiveness and efficiency in achieving client goals. Accountability can be accomplished by information secured through evaluation techniques and more specifically through social research (Tripodi 1974).

ROLE OF EVALUATION RESEARCH IN SOCIAL WORK PRACTICE

The literature recognizes that evaluation research is related to the need for accountability in social work practice. At a workshop sponsored by the American City Corporation in 1971, it was pointed out how important research is to policy making. The 1971 workshop concluded that:

1. The current decade will be a time of action in urban affairs on a scale never before imagined...it is imperative to clarify and plan how evaluation research can be made useful to policy makers, program designers and analysts and the day-to-day operators of life support systems.

2. In these days of large government programs intended to reduce poverty, develop communities, prevent delinquency and crime, control disease, and reconstruct cities, the 
predominant rhetoric is that of planning, pilot projects, experimental, and demonstration programs--and evaluation. In a few treasured instances there is a well considered, realistic, and workmanlike plan for getting some fairly reliable answers to the questions of what worked and why.

3. This is the age of evaluation research, not that evaluation is new, but in contrast to other practical research modes like the social survey, applied research, and action research, evaluation is the "in" thing, evaluation is always concerned in some way with a judgment of worth (emphasis added).

The reasons for this (evaluation research) are not hard to discern according to the report of the American City Corporation Workshop, 1971. In the early 1960's, the Federal government began large direct service endeavors in delinquency, crime, poverty, and urban life. These programs all but ignored existing agencies and created new structures with the promise that they would have an immediate, positive impact on "social problems." When this did not occur, the demand for evaluation arose (Chaiklin 1971).

The report of the 1971 workshop states that the response to these concerns has been long on diagnosis and short on developing procedures to enable evaluation research to be effective. The following principles are suggested for making evaluation research useful (Chaiklin 1971): 
The first is that some elemental components of the nature and limits of science must be shared by all participants in the evaluation process, from consumer to policy maker.

The method of science is different than its techniques. Science is an objective, logical, and systematic way of accumulating knowledge... it always requires a theoretical perspective to give meaning to whatever information is developed. The mere collection of data does not constitute evaluative or any other kind of research.

Relatively few programs and projects permit definitive and full-scale evaluations. For large programs, the major reason is not the lack of critierion variables or research methodology but because there is almost no clear policy to measure outcomes against.

For example, the Juvenile Delinquency and Youth offenses Control Act of 1961 was supposed to be a comprehensive attempt to deal with delinquency. Yet its main activities were with employment, education and community organization. Each of these factors is a variable related to delinquency. There are also many others, for example, the family, nutrition, and religion. The report continues with the comment that a truly comprehensive approach would have assessed the weight of each factor, tried to understand what the connection between the variables was and planning accordingly. The conclusion off the report is: these things were not done; the absence of a delinquency policy was clear from 
the outset. The report concludes that this program was little more than a limited test of the sociological theory which says that delinquency comes from blocked opportunity. The delinquency program was evaluated and few project reports were made public; 50 million dollars was expended on this program; and it was not enough to do the job. Chaiklin concludes that research is expensive and that good researchers are hard to find.

The absence of policy, of a program of sufficient size to warrant a full-scale evaluation, or of ideal research conditions does not mean projects cannot be judged on a scientifically sound basis. Science deals in probabilities and not absolutes. Within these limits, any program can be evaluated.

Hirsche and Selvin describe the frequency with which research findings are called into question by critics who ask for more in the way of theory, method, and data analysis than the study claimed to encompass.

Some recent opinions expressed in the social sciences reflect the view that statistical significance tests are overused. These opinions comment that in evaluation research, the need for probability tests and complex methodology is very small indeed. Flanagan (1971) states that experience over many years suggests that, in most practical situations, simple descriptive statistics are more likely to be correctly used and correctly interpreted than the more complicated ones, and simple methods of statistical analysis and inference more use- 
ful in practice than those that are more elaborate and involved.

An evaluation researcher should provide simple and clear explanations about what he is doing, if he is doing his job correctly.

Chaiklin's second principle of making evaluation research useful is: the evaluation researcher must meet the needs of those who will use his report and those who participate in the evaluation.

Ferman (1969) talks of the social dimensions of evaluation. By this he refers to the differing perspectives of evaluator, administrator, practitioner, and sponsor.

To this list can be added the consumer, the public, the legislator and any other relevant group that is related to the program.

Because research serves many functions, the relative balance between complementary and conflicting needs need to be assessed for every situation. It is perfectly possible to evaluate a program which at the sponsor level is looking for cheaper and more effective ways to rehabilitate people and, at the administrative level, to increase the budget by making the demonstration program a permanent part of the agency's operations.

Fishman writes that any systematic approach to explanation--be it case studies, participant observations, field surveys or careful theoretical inductions or deductions--has been considered an acceptable approach to scientific explanation, particularly where the subject matter is complex or 
novel.

What emerges as the evaluator's major skill is his ability to translate the actualities of practice into policy terms. Taking account of the needs of all the actors in the evaluation process requires that the evaluator must use a sufficient range of research techniques to make the evaluation meaningful to those who are at each level he must communicate with. His report should reflect all these concerns.

Chaiklin's third and final principle: evaluation research will only be useful when there is provision for implementation and reevaluation.

In most evaluation structures, the researcher is in a peculiar position. He possesses a great skill, but he has little formal power in agency hierarchy. If he is part of the agency, he is usually considered staff and has no line authority. Most usually he is an outsider who simply turns in his report and leaves. Finally, Chaiklin points out that turning in the report is probably only the first stage of the evaluation, not its completion. 
III. RESEARCH PROGRAM COMPONENTS AT PSU

A statement of goals of the research component and of research policies approved by the Portland State University faculty was circulated to members of the faculty in November, 1973.

At that time, a research committee, including faculty and student members, was planning to work on a new set of standards for student research and procedures to follow in the future.

GOALS OF THE RESEARCH COMPONENT

OF THE CURRICULUM -. 1973*

A. Premises

1. The school cannot undertake at this time a major concentration in research designed to prepare any substantial number of students for a career in research. On an individual basis, however, using resources available, the school will try to provide advanced work for those with special interest and ability in research.

2. Responsibility for inculcating the scientific outlook, its application to practice, and (for) the reinforcement of research skills is shared by all

\footnotetext{
* The Manual on Thesis and Practicum Advising,
} PSU School of Social Work, 1973. 
the faculty in all courses. These include a firm commitment to the principles of reasonable argument, the habit of demanding verifiable evidence in support of assertions with an empirical reference, a discriminating judgment as to the merits of statements and viewpoints, awareness of the limitations of observations, the ability to translate real life problems into research problems, and to converse on an equal level with colleagues in social work and in associated disciplines.

3. Responsibility for imparting research skills lies with the research faculty, though not exclusively.

4. Due respect must be maintained for the prerogatives and discretionary judgment of the professionally responsible and autonomous teacher both with respect to these goals and to the means of achievement.

5. This statement of goals is both dated and subject to continuing review.

6. The research goals are based on a continuum of undergraduate preparation, through the doctoral level. The average student should be capable of continuing toward the doctorate in social work or interdisciplinary fields at this and other universities.

7. It is the responsibility of the school to make 
possible the achievement of these goals through appropriate learning experiences.

B. Levels Reached at Graduation

1. All students should be able to read, understand and criticize the professional social work related literature in his field.

2. All students should have familiarity with and skill in the use of the major sources of accessible data and the major bibliographic resources in the fields of social work and related fields in his specializations.

3. All students should have familiarity with the major applications and contexts of social work research with respect to the improvement of practice, the rational and responsible management of agency operations, the formulation of policy, its implementation and the assessment of programs.

4. The average student should be able to obtain an understanding of the meaning of statements and symbols he does not know, by his own efforts or through consultation.

5. The average student should have demonstrable proficiency in the judicious and appropriate use of elementary statistical techniques, both descriptive and inductive, parametric and non-parametric. 6. The average student hsould have a demonstrable 
knowledge of the basic concepts of research design.

7. The average student should have the demonstrable ability to lay out an appropriate design for the research of commonly encountered professional problems in his field, and to use consultation.

8. The average student should be able to conduct directed research with the minimum of supervision, as member of a team, appropriate to his work setting.

9. The average student should have an awareness of the existence of some more advanced or sophisticated statistical and research techniques requiring consultation.

10. The average student should be able to present his research according to the canons of report writing, and to use techniques requiring consultation.

11. The superior student should be able to help others, to guide and to coordinate a group effort, to anaIyze and criticize positively reports submitted to him, to suggest and use appropriate common statistics with possible varients, to suggest appropriate solutions to problems of design and execution presented by his colleagues, to use calculators and computer resources, to conceive and undertake individual research and to prepare his own manuscripts for publication in appropriate media.

C. Research Concepts 
mean, grouped data median grouped data chi square

student's standard score

F ratio

standard deviation

standard error

rho

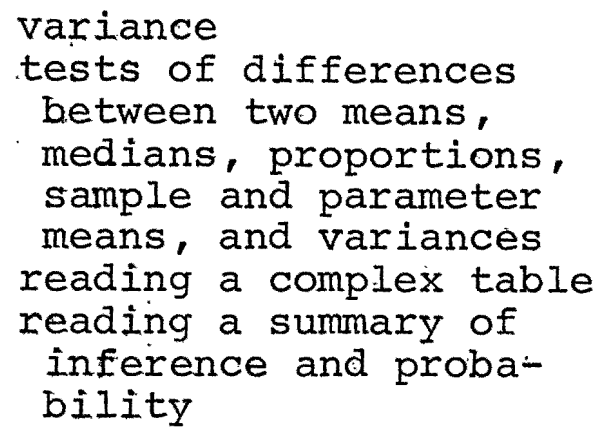

2. Superior students will be introduced to:

\author{
analysis of variance \\ regression \\ prediction \\ estimation \\ use of a calculator \\ some alternate measures
}

3. All students will have demonstrated their ability to use the measures appropriately with respect to assumptions, conditions, choices, use of statistical tables, general reasons, uses and abuses and relation to concepts.'

4. Demonstration of ability may be in three modes:

a. calculation by hand or calculating aids;

b. use of a time sharing system, including the vocabulary, operations and interpretation;

c. use of a computer system to obtain desired statistical output, and its meaningful interpretation.

E. Student Research

1. It is a realized goal through the requirement for graduation for all students to complete or participate in a research project which embodies evi- 
dence of the successful integration of the major elements of previous learning in social work research, together with learning in process, including problem identification, rationale, specification of design and methodology, data collection, data analysis and a written report.

2. A goal is to assist students in applying their research skills and knowledge while students do course papers and analyses, as participants in committee studies, in institutional research, and in their field placements, as well as in the research of faculty members.

3. A goal is to help students identify areas of interest for research after graduation, to begin preliminary work and to carry through a lasting interest in research and publication.

4. A goal is to encourage and help students publish and otherwise disseminate information about their research project.

F. Faculty Research

1. A goal of the research staff is to be a resource for the research of other members of the faculty, and in the research aspects of grants.

2. As an example, a goal is to utilize the research of the faculty and for the research faculty to engage in research; the reading of papers and 
publications.

3. A goal is to encourage the entire faculty and school to participate in the systematic advancement of knowledge and in the research education of stu-. dents, especially by acting as advisors to student research projects.

G. General

The goal of the school is to maintain a program and product at least equal to those of our sister institutions in the Northwest and, above all, in keeping with the increasing needs of social work in the foreseeable future. 


\section{JUSTIFICATION FOR THE RESEARCH PROGRAM*}

The research policy statement of the School of Social Work at Portland State University justifies the need for the research curriculum for all students in the masters program in the following manner:

A. A masters degree is not awarded simply upon the passing of a set. of courses. In social work, we have arranged with the graduate office for the research accomplishment to be a part of the final evaluation of the student's professional competence and it stands in lieu of a final comprehensive examination. Faculty and students have several times chosen the research alternative.

B. Students and faculty have several times chosen this objective for ourselves, that we will turn out graduates who are capable of advancing knowledge and practice in the profession and in their own career advancement, no matter what their field of specialization. The alternative is a reliance upon the graduates of other schools for leadership, ideas and knowledge.

C. While our school chose its role from the beginning, realistically our graduates are in competition with

*The Manual on Thesis and Practicum Advising, PSU School of Social Work, 1973. 
those from other universities. The other schools in the Northwest have strong and growing research emphasis.

D. Trends in Social Work and pressures from without demand a greater competence in research: to read a more sophisticated literature; for individual, program and wider accountability; for self-reliance in studying our own problem areas; and to improve our position relative to other professions and professionals with whom we deal.

E. Much depends upon the prestige we carry within the university. The research product is a visible means by which others can judge the quality of our faculty, students and program.

F. These and other reasons have led us to justify a collective overriding of individual aversions to required research. 


\section{METHODOLOGY}

A. RESEARCH GOALS AND OBJECTIVES

The goal of this study is to provide useful information for:

1. evaluating the existing social work research program and policies. A research program manual has been prepared and is available for students to become familiar with the program; however, no attempts were made previous to our study to determine whether the respondents had extensive knowledge of the program components and policies. It is our intention that this study is an exploration of attitudes; it is not meant to be a final measurement of the worthwhileness of the existing social work program. In our study, attitudes are considered to be subjective opinions of individual respondents, not exact measurement;

2. planning a research curriculum with optimal relevance to social work. In our study, we recognize that relevance is dependent on the professional objectives and background of the respondent and that the degree to which a respondent favors a strong research component is likely to be related to one's professional role in social work or a related field. 
The objectives of this study are to explore and to evaluate attitudes within the social work field regarding :

1. what particular research skills are necessary for effective social work practice in a social work setting; necessity is recognized as a variable depending on respondent's educational background, type of employment, and professional goals;

2. how adequately social work students are prepared to use these skills, recognizing a variance in individual interests and goals;

3. the need for research skills for all social work students recognizing a variance in needs of society, clients and other variables; and

4. the level of interest generated by the proposal of a research seminar for agency personnel. Recognized variables here include position of personnel, type of research subject, and type of course, or consultation offered.

B. DEVELOPMENT OF THE QUESTIONNAIRES

1. FIRST QUESTIONNAIRE

In April 1974, a total of 187 questionnaires were distributed to the entire population of Portland State University second-year social work students, the Social Work faculty, field instructors, and to the field placement social work agency directors. 
Because research experience and knowledge and levels of responsibility among respondents varied greatly, we selected a small and highly general sample of basic research skills for the study.

The questionnaire was devised to measure:

a. attitudes regarding the necessity for the following specific research skills within the social work setting:

(1) problem definition;

(2) realistic goal and objective formulation;

(3) population measurement skills;

(4) data collection;

(5) sampling techniques;

(6) analysis of data;

(7) evaluation of research projects;

(8) application of evaluation to ongoing studies.

b. Attitudes regarding the adequacy of student preparation for the actual practice of these skills; recognizing that a judgment regarding adequacy is dependent upon the experience, level of responsibility and knowledge of each respondent;

c. attitudes regarding the requirement of a research experience for all social work students; and

d. attitudes regarding the proposal of a research seminar for agency personnel. Variables are type of personnel, type of research subject, 
and whether seminar would include instruction or consultation or both.

of the total 187 questionnaires, 131 were returned, constituting a 70 per cent response. No provisions were made in our study to determine if respondents were significantly different from non-respondents or if research oriented respondents returned more questionnaires than non-research oriented persons.

Responses were recorded, tabulated, and evaluated according to the populations polled, which were divided into three groups:

1. second-year graduate students;

2. faculty and field instructors; and

3. agency directors.

Individual comments which were considered pertinent to the study were then summarized according to each particular population group. Classroom and field instructor areas of specialization were not identified in their responses, or separated according to direct service or community organization practice.

An analysis was formulated on the basis of:

a. a comparison of the responses of students, instructors and agency directors and of the variables associated with those responses;

b. similarities and dissimilarites of attitudes and of the intensity of expression in the res- 
ponse; and

c. trends emerging from the study related to the overall population sampled, bearing in mind that student and professional opinions were likely to change as professional responsibilities and knowledge increase from casework to higher levels of career performance and as students increase their knowledge of and experience in research.

\section{SECOND QUESTIONNAIRE}

To add another dimension to the study, a second questionnaire was distributed to entering social work students during the first two weeks of the fall term 1974 at Portland State University; previous exposure to Portland State University research classes and agency research activity was minimal. We recognize that some students may have had previous social work experience, but little or no experience with the research component in the graduate social work curriculum. Exceptions could have been students who earned undergraduate certificates in social work at Portland State University.

In October of 1974, a total of 95 questionnaires were distributed to the total population of Portland state University first-year social work students.

Because this population had not been introduced to the research component at Portland State University 
School of Social Work, this questionnaire was devised to measure only:

a. attitudes regarding the necessity of research skills for all social work students; and

b. attitudes regarding research activities in social work agencies.

of the total 95 questionnaires, 54 were returned, constituting a 57 per cent response.

Responses to the first question were recorded and tabulated and individual comments were summarized.

Responses to the second question were summarized into particular avenues of opinion regarding the role of research activities in social work settings. These findings were utilized not only as a comparison to attitudes expressed in responses by the first three groups, but also as an extended dimension of our study.

C. MEASUREMENT OF POPULATION

1. SECOND-YEAR STUDENTS, SPRING, 1974

a. With reference to attitudes regarding research skills column I indicates the percentage of positive response to each of eight research skills which may be considered valuable in a social work setting. Positive response refers only to whether respondents believe that or think students need to learn these research skills. Responsdents were asked to make a 
check mark next to a specific skill if they believe students are receiving adequate preparation for the use of that specific skill. b. With reference to attitudes regarding student education, column II indicates the percentage of positive response regarding the adequate preparation of social work students for the use of these eight skills in a professional setting .

RESEARCH SKILIS*

1. Definition of a problem for social research.

2. Formulation of realistic goals and objectives.

3. Utilization of methods of population measurement.

6. Analysis of data for specific social work purpose.

7. Evaluation of a research project.

80

8. Evaluation of existing studies and application of results to ongoing work in program development.

* Percentages are related to total number of returned questionnaires. Numerical response is listed in Chapter VI (A). 
c. With reference to attitudes regarding the necessity of of a research cirriculum for all social work students, the following response is recorded in percentages:

YES : $77 \%$ NO: $13 \%$ UNDECIDED: $10 \%$

(1) Quantity of research, type of research, and level of research were not specified in the questionnaires.

(2) A "NO" response indicates a research curriculum is not necessary for all social work students.

(3) A "UNDECIDED" response indicates respondent does not have a yes or no opinion to offer in response to this question.

d. With reference to attitudes regarding interest in a proposal for research seminars for agency personnel, the following response is recorded in percentages:

YES : $68 \%$ NO: $18 \%$ UNDECIDED: $14 \%$

The questionnaire does not specify:

(1) type of seminar;

(2) whether response is an expression of interest for respondent's self or for other personnel.

e. Summary of written responses of second-year students : 
A significant number of responses of secondyear students indicated that direct service techniques do not require advanced knowledge in the field of research methodalogy.

However, considerable evidence from the comments indicates a necessity for a basic knowledge of research procedures so that existing studies may be evaluated and utilized in an ongoing process.

An almost universal comment from the social work students was that advanced research and actual techniques should be assigned to experts in the research field: Responses do not specify whether it is the responsibility of the social work education to train the experts and, if so, should it be Portland State University or some other school. There are different meanings associated with the term "expert" which is not defined either on the questionnaire or in the responses.

Research seminars for agency personnel were evaluated as useful and helpful, but comments indicated that the degree of usefulness would depend upon the function of the agency. Some of the factors to be considered in regard to seminars are accountability, improvement of practice, and 
self-evaluation.

2. FACULTY AND FIELD INSTRUCTORS

a. With reference to attitudes regarding research skills, column I indicates the percentage of positive response to each of eight research skills which may be considered valuable in a social work setting. Positive response refers only to whether respondents feel or think students need to learn these research skills.

b. With reference to attitudes regarding student education, column II indicates the percentage of positive response regarding the adequate preparation of social work students for the use of these eight skills in a professional setting. Respondents were asked to make a check mark next to a specific skill if they believe students are receiving adequate preparation for the use of that specific skill.

\section{RESEARCH SKIILS**}

1. Definition of a problem for social research.

2. Formulation of realistic goals and objectives.

3. Utilization of methods of population measurement.

4. Development of relevant instruments for data collection.
$I \quad I I$

$97 \quad 59$

100

44

47

25

72 
5. Application of appropriate and scientific sampling techniques.

6. Analysis of data for specific social work purpose.

7. Evaluation of a research project.

8. Evaluation of existing studies and application of results to ongoing work in program development.

* * Percentages are related to total number of returned questionnaires. Numerical response is listed in Chapter VI (A). Responses were not correlated with areas of specialization, i.e. direct service or community organization.

c. With reference to attitudes regarding the necessity of a research curriculum for all social work students, the following response is recorded in percentages:

YES: $47 \%$ NO: $3 \%$ UNDECIDED: $50 \%$

(1) Quantity of research, type of research, and level of research were not specified in the questionnaire.

(2) "NO" means a research curriculum is not necessary for all social work students.

(3) "UNDECIDED" means respondent does not have a yes or no opinion to offer in response to this question.

d. With reference to attitudes regarding interest in a proposal for research seminars for agency personnel, the following response is 
recorded in percentages:

YES: $63 \%$ NO: $10 \%$ UNDECIDED: $27 \%$

The questionnaire does not specify:

(1) type of seminar;

(2) whether response is an expression of interest for respondent's self or for other personnel.

e. SUMMARY OF COMMENTS OF FACULTY AND FIELD INSTRUCTORS

Faculty and field instructors indicated that a general understanding and appreciation of research theory is necessary in social work; students should be made thoroughly familiar with research methods and social work design. The 50 per cent "undecided" response to question 3 (the necessity of a research curriculum for all social work students) appears to be in conflict with written comments regarding which students need research knowledge.

A significant number of responses, approximately 20 per cent, indicated that students should be prepared and able to complete a research project for use within the social work setting. Approximately the same number indicated that the student should be knowledeable enough to make use of a research professional or consultant. Evaluation skills were stressed as important 
in almost all incidences; and, for all students, the indication was that special programs should be designed to meet individual student needs.

Research seminars for agency personnel were regarded favorably if they could be specific and deal with agency problems in research and with actual ongoing research projects. Some comments indicated awareness of the relationship of seminars to accountability, to improvements of practice, and to self-evaluation.

3. AGENCY DIRECTORS

a. With reference to attitudes regarding research skills, column I indicates the percentage of positive response to each of eight research skills which may be considered valuable in a social work setting. Positive response refers only to whether respondents feel or think students need to learn these research skills.

b. With reference to attitudes regarding student education, column II indicates the percentage of positive response regarding the adequate preparation of social work students for the use of these eight skills in a professional setting. Respondents were asked to make a check mark next to a specific skill if they believe students are receiving adequate pre- 
paration for the use of that specific skill:

RESEARCH SKILLS***

1. Definition of a problem for social research.

2. Formulation of realistic goals and objectives.

3. Utilization of methods of population measurement.

49

66

for data collection.

40

tific sampling techniques.

6. Analysis of data for specific social work purpose.

7. Evaluation of a research project.

8. Evaluation of existing studies and application of results to ongoing work in program development.

80
II

51

20

*** Percentages are related to total number of returned questionnaires. Numerical response is listed in Chapter VI(A). Responses were not correlated with areas of specialization, i.e. direct service or community organization.

c. With reference to attitudes regarding the necessity of a research curriculum for all social work students, the following response is recorded in percentages:

YES : $65 \%$ NO: 15\% UNDECIDED: $20 \%$

(1) Quantity of research, type of research, and level of research were not specified 
in the questionnaire.

(2) "NO" means a research curriculum is not necessary for all social work students.

(3) "UNDECIDED" means respondent does not have a yes or no opinion to offer in response to this question:

d. With reference to attitudes regarding interest in a proposal for research seminars for agency personnel, the following response is recorded in percentages:

YES : $75 \%$ NO: $10 \%$ UNDECIDED: $15 \%$

The questionnaire does not specify:

(1) type of seminar;

(2) whether response is an expression of interest for respondent's self or for other personnel.

e. SUMMARY OF COMMENTS OF AGENCY DIRECTORS

Agency directors were unanimous in their comments that all social work students must have enough background in research to read, to understand problems, and to evaluate the work of others. Written comments conflict with the 20 per cent "undecided" response, regarding the necessity of a research curriculum for all social work students.

Less than ten per cent of the comments indicated that all students should be able to 
actually carry out and complete a research project, but a significant number of written comments indicated that knowledge or familiarity with basic research skills is needed in the agency setting.

Agency directors involved in community organization provided the strongest response in favor of a more sophisticated training in research, but there was no overall indication that special programs should be developed for individual students. Research seminars were generally regarded very favorably; comments indicated that these seminars should be able to deal with the individual problems of the agencies involved.

In our attempts to account for the differences in response among students, instructors, and agency people, we recognize the following variables:

1. areas of specialization. Agency directors in community organization and second-year students responded more strongly in favor of research training than other respondents who may or may not be in direct services;

2. research experience and knowledge of the respondent; and

3. needs of clients, degree of agency and professional accountability to society, and the demands of professional level of practice, both on agency and academic levels. 
4. FIRST-YEAR STUDENTS, Fal1 1974 (second questionnaire)

a. With reference to the first question, response was tabulated as follows: Are research skills necessary for all social work students: POSITIVE YES QUALIFIED YES 12

POSITIVE NO 11 QUALIFIED NO 8

percentage of positive response

to second questionnaire: $64.8 \%$ of 54 responses percentage of negative responses

to second questionnaire: $35.2 \%$ of 54 responses

b. Written responses to the second question regarding attitudes toward research in social agencies were summarized according to negative and positive attitudes. See section VI (B) . 


\section{ANALYSIS AND EVALUATION OF THE RESPONSES}

\section{A. FIRST QUESTIONNAIRE}

The overall response to the first questionnaire was as follows :

1. second-year students: out of 76 questionnaires, 56 were returned representing a 74 per cent response;

2. faculty, field instructors: out of 64 questionnaires, 32 were returned representing a 50 per cent response;

3. agency directors: out of 47 questionnaires, 43 were returned representing a 93 per cent response;

4. a combined total: out of 187 questionnaires, 131 were returned representing a 70 per cent response.

The overall response to the second questionnaire by first-year students was as follows: out of 95 questionnaires, 54 were returned representing a 57 per cent response.

Out analysis of the total response indicates that there is more concern for research skills in an agency setting than in the school setting, and that perhaps faculty and supervisors who are not involved with research do not choose to make an assessment or are not involved personally in the research curriculum. 
With reference to the necessity for particular skills in social work, the following indicates those skills, and the percentage of positive response by over 80 per cent of each particular group:

1. second-year students:

\section{Skill}

realistic goal information

evaluation and application

of existing studies

evaluation of research
Positive Response

$83 \%$

$82 \%$

$80 \%$

2. faculty and field instructors:

\section{Skill}

*realistic goal formulation

problem definition

research project evaluation

application of evaluation

analysis of data
Positive Response

$100 \%$

$97 \%$

$96 \%$

$94 \%$

$81 \%$

* the questionnaire does not define what would be realistic. For some respondents, practical goal formulation is realistic. However, the responses do not indicate priorities or how important and urgent needs of social work are determined.

3. agency directors:

\section{Skil1}

realistic goal formulation

problem definition

application of evaluation
Positive Response

$91 \%$

$86 \%$

$80 \%$

It is interesting to note that realistic goal formulation was the skill considered most necessary by all three 
groups; also the ability to apply evaluation of research to ongoing projects was considered important to all three groups. Problem definition was considered a necessary skill by faculty and field instructors; it was not indicated thus by the student group. Evaluation and analysis of data were positively rated only by the faculty and field instructors group, implying that this group may be more concerned with program development issues than students and agency directors.

On the basis that the 50 per cent questionnaire response by faculty may indicate a response from those particularly interested or involved in research, it may possibly be assumed that this response would represent a population more familiar with the skills and more likely to recognize their value in the setting. Therefore, in this case, this could very well be a biased response.

All three groups responded that skills least necessary in the social work field are:

1. application of appropriate and scientific sampling techniques;

2. development of relevant instruments for data collection; and

3. utilization of methods for population measurement. These are demographis variables which may be necessary to assess research variables. Therefore, we wonder why responses indicate that such important skills are least 
necessary. For some, it may be lack of knowledge; we have no explanation for other responses. Some professionals would argue that sampling and instrumentation are central to research, upon which all else depends ( 1 and 2, above).

This agreement may indicate that these skills are regarded as more sophisticated, technical skills and could possibly be relegated to professional research staffs (as indicated by the comments) and that responses show unawareness of the importance of measuring demographic variables in order to assess research variables, techniques especially useful to community organization and planning and to higher administration.

With reference to the training or adequate preparation of students in these particular skills, the positive response among all three groups was 40 to 60 per cent less than the positive response to the skills which were indicated necessary. The study did not specify the specific meaning of adequacy or answer the question: adequate at what level? There is agreement that understanding literature, participating in studies, conducting or grading research, using expert help are all recognized areas for adequate preparation. However, no provisions in the study were included to distinguish which skills demonstrate more adequate preparation. For students, are differences of opinion related to instructor's point of view? Responses related to adequate training or preparation are recorded according to group and percentage of positive response: 
1. students:

\begin{tabular}{|c|c|}
\hline Skill & Positive Response \\
\hline problem definition & $61 \%$ \\
\hline research project evaluation & $41 ㅇ ㅛ ㅇ$ \\
\hline realistic goal formation & $41 \%$ \\
\hline faculty, field instructors: & \\
\hline Skil1 & Positive Response \\
\hline problem definition & $59 \%$ \\
\hline realistic goal formation & $44 \%$ \\
\hline research project evaluation & $44 \%$ \\
\hline agency directors: & \\
\hline Skil1 & Positive Response \\
\hline problem definition & $52 \%$ \\
\hline realistic goal formul & $42 \%$ \\
\hline
\end{tabular}

There was consensus among the three groups regarding student preparation for particular skills; all three groups rated the technical skills at the bottom, with regard to training as well as necessity.

It seems evident by recognition of the margin in positive response which exists between the skills believed to be necessary and the adeptness of students to utilize these skills that there is some implication among responses that students are not being trained adequately to use the most necessary skills. There does seem to be some correlation between the attitudes relating to necessity of skills and student preparation in these skills, which may indicate that 
the most valued skills are being dealt with in the curriculum, but perhaps not to the level of competence regarded as necessary. This implication is reflected by the response of all three groups.

A summary of the response regarding the necessity of a research curriculum for all social work students indicates the following:

\begin{tabular}{llrc}
\multicolumn{1}{c}{ GROUP } & YES & NO & $?$ \\
1. students & $77 \%$ & $13 \%$ & $10 \%$ \\
2. faculty, field instructors & $47 \%$ & $3 \%$ & $50 \%$ \\
3. agency directors & $65 \%$ & $15 \%$ & $20 \%$
\end{tabular}

Students valued research curriculum more than research seminars later; however, faculty and agency personnel placed higher value on research seminars. One question raised here is whether the latter recognized they did not have enough research education; whether they needed to "catch up" after graduation or make up for what they missed as students.

A summary of the response regarding the interest in a proposal for research seminars for agency personnel indicates the following:

\begin{tabular}{lccc}
\multicolumn{1}{c}{ GROUP } & YES & NO & $?$ \\
1. students & $68 \%$ & $18 \%$ & $14 \%$ \\
2. faculty, field instructors & $63 \%$ & $10 \%$ & $27 \%$ \\
3. agency directors & $75 \%$ & $10 \%$ & $15 \%$
\end{tabular}

Again, a similarity in the response indicates all three groups favorable to a research curriculum for all 
social work students as well as the interest in the notion of providing research seminars for agency personnel. And again; the lower positive response on the part of the faculty, field instructors group may imply a greater involvement with other social work committments.

In conclusion, we find the implications of the study are:

1. research skills are considered necessary by persons involved in social work and that particular skills of problem definition, evaluation and application are believed to be more necessary than the technical skills relating to measurement and techniques;

2. students are being trained in those skills regarded as most necessary to social work, but possibly not to the level of competence believed necessary for the most effective functioning in the social work field; and

3. that further training by means of research seminars for agency personnel is regarded favorably.

Although many varying attitudes and comments were expressed within each of the groups, it may be noted that two basic trends seemed to emerge from the study:

1. research skills are defined as necessary for social work personnel with the view that these skills will be utilized for personal involvement in research projects; 
2. research skills are defined as necessary for social work personnel with the view that they are to be utilized to evaluate only, or in conjunction with professional consultation. This view holds that a general knowledge of research procedures promotes a better use of professional research facilities. The results of this study provide some additional implications for ongoing planning of research experience in social work education and an indication that this is a topic which could be subjected to further study, statistical tests, and continuous evaluation reseárch.

Further implications of this study are that:

1. all respondents favor some research experience in social work education, either for specialist or consumer;

2. all respondents agree that some skills are more necessary, generally, for effective practice than are other skills;

3. there is strong agreement among all population groups that research education is valuable; however, type and level of education are subject to individual and agency goals;

4. there is respect for a research point of view and strong interest in becoming effective consumers of research findings; and 
5. responses recognize that research knowledge is significant in contributing to effective social work practice:

B. SECOND QUESTIONNAIRE

The response of the first year students regarding a research curriculum required of all social work students indicated, in summary, a dichotomy in attitudes:

1. a research curriculum should be required for social work students. It is necessary for the following reasons :

a. understanding the use of research;

b. the useful evaluation of projects, work;

c. intelligent assessment of research materials;

d. guidelines to measure effectiveness, priorities of needs.

2. a research curriculum should not be required for the following reasons:

a. research should be an elective, for students primarily interested in research aspects of social work; and

b. research should be incorporated in a core class to provide only a basic method for understanding research literature.

The response regarding research in agency settings was unified in that all first year students believed-research essential to agency function. These functions were related 
primarily to two areas:

1. devising programs in the following areas:

a. assessment of needs;

b. as a means to develop focus and to upgrade quality of services;

c. must be ethically performed, not politically;

d. objective planning;

e. financial resources;

f. as observation rather than manipulation.

2. evaluating programs:

a. evaluation increasingly critical to action programs with scarcity of funds;

b. agencies can benefit if change is indicated and can be implęmented;

c. to determine creditability;

d. to implement staff changes.

Concensus was evident in the attitudes that research must :

1. be related to goals of agency;

2. meet needs of public;

3. predict future action and trends.

only two students expressed "serious doubts about the effectiveness of research in behavioral sciences." The opposing view, reflected by an overwhelming majority, is that agencies must have research built into their structure. The general concensus in responses seems to indicate that the 
direction of research should be guided by highly professional, specifically trained personnel of the agency. 


\section{CONCLUSIONS AND RECOMMENDATIONS}

Student, faculty and agency directors" responses to this study support our conclusion that research is an integral, invaluable and necessary adjunct to the social work process and that a meaningful evaluation of a research program must relate to the two basic questions:

1. Why research knowledge and experience?

2. How best can research knowl'edge and experience be taught? What is feasible in terms of structure and use of faculty and agency cooperation?

The first question then refers directly to the very justification for a research curriculum at Portland State University. This justification relates to several basic considerations:

1. Originally, it was a defined choice of both faculty and students to provide a research program in the curriculum; as noted, all responses indicate that a research program must be retained as a valid component of social work.

2. A concern for the reliance upon the graduates of other schools has been expressed as justification. There is support. among responses that all research activity could be accomplished entirely by professional research firms unrelated to the university or to the social work field, implying reliance on 
ather disciplines or institutions. However, most respondents in all populations indicated that, although professionals should perform the technical research activities, a basic research curriculum is necessary to provide needed tools for understanding and evaluating research activities.

3. Another concern in the development and justification of a research curriculum was the factor of competition with other schools of social work. Responses indicated that this was not a consideration of students; however, several faculty comments indicated that a research' component is a necessary segment of the social work curriculum "in yarying degrees relating to statistical proficiency" of the individual student.

4. Justification for the original research component refers finally to accountability and self reliance. Accountability is strongly supported by students, . faculty, and agency personnel as not only the prime reason for supporting a research curriculum, but also as the concept that accountability should always be a basic focus of research related to agency activity, program development, and evaluation.

To further explore the "why research" question, responses have been summarized and viewed with relation to the 
basic goals and premises of the research component as written in 1973:

Why research knowledge and experience in social work? In order to provide an answer to this question and to give some useful meaning to the data, responses of our study have been related to the specific goals and premises of the research component.

Responses indicate approval of the school's premise that there is no demand at this time to provide preparation for a research career for a significant number of students. However, student responses indicate unawareness of available resources to provide advanced work.

Regarding faculty comitment to research, we have no response indicating disagreement with inculcating the scientific outlook, its application to practice, and the reinforcement of research skills by all faculty in all courses. In fact, there are indications of firm commitment to the scientific outlook and method; however, fifty per cent of faculty responses do not agree with the premise that a research curriculum is necessary for all social work students. Philosophically, the faculty supports research oriented principles, but there is disagreement regarding content and student population factors. In other words, faculty response is not clear regarding: Who should be taught what?

Responses indicate no conflict with the premise that 
the responsibility for imparting research skills lies with the research faculty.

We have no responses relevant to the premise that "due respect must be maintained for the prerogatives and discretionary judgment of the professionally responsible and autonomous teacher both with respect to these goals and to the means of achievement."

Responses of all populations agree with the premise that goals must be subject to change and to continuing review. Relevance and accountability rate as a prime consideration for the justification of research knowledge and experience.

We have no responses relevant to the premise that research goals are based on a continuance of under-graduate preparation through the doctoral level. However, we support the continuum approach on the basis that it encourages further study.

Responses support the premise that the school is responsible for providing appropriate learning experiences. Concerns of the respondents relate more to how research knowledge can be effectively taught and to achieve what educational and professional purposes.

What should students know at the conclusion of the Master of Social Work program?

Responses of all populations support the goal that all students should be able to: 
1. read, understand and criticize the professional social work related literature;

2. have familiarity with the professional social work related literature;

3. have familiarity with the major applications of research findings to practice;

4. utilize consultation when in doubt about meanings of symbols and technical statements.

Regarding the goal that the average student should have demonstrable proficiency, responses indicated a reticience to accept the necessity of proficiency in statistical techniques for ali students.

Finally, from an evaluation of the responses, we hoped to uncover implications with reference to the second basic question: "How can research knowledge and experience be taught?" In summarizing both statistical data and individual comments from all populations, several trends of thought emerge:

1. The research skills regarded most important by all social work students relate to reading, understanding and evaluating research studies.

2. These skills must include the individual ability for realistic goal formation, and the evaluation of existing studies, as well as realistic problem definition.

3. There is an indication among respondents that all 
students are not being taught these skills to the same degree; that there may exist a large degree of difference between individual classroom involvement in research activity and acquisition of knowledge.

Further, in rel,ating research to social work practice in the agency and the community, basic trends in attitudes are:

1. There is an absolute need for relevance, accuracy, and a sophisticated, highly trained research personnel.

2. There is a need for research personnel capable of focusing upon program development, justification for program activity, relevance of existing job positions and their functions within the ageney.

3. A small percentage of students wish to be involved exclusively in the research activity of social work.

On the basis of the responses, particularly those of the student population, it may be assumed that there exists some individual aversion to research which may be related, to the mathematical and/or statistical background of the student: We believe that much of student reticence and "fear" involving a research requirement may evolve from $a$. lack of knowledge and experience. Also, there is indication that statistical concepts, actual administration of testing 
procedures, and-memorization of specific terminologies are viewed as components with whilch some students will never realistically become involved.

Although a few responses indicate that students may appear to be somewhat anxious or intimidated by the research requirement, they also express the attitude that there is need for research activity in the social work profession to evaluate, to understand the development and the application of research studies which have been completed, including the research projects of prior graduates.

A proposal for a realistic approach to the "how to teach" problem may be two-fold:

1. We recommend that a general, broad course in research activity involving problem definition and evaluation techniques, stressing understanding of completed research studies and findings related to behavioral sciences, program evaluation, and the use of research in social work practice be included in the core curriculum required of all first year students. This core research curriculum could either be taught to all students simultaneously in the core classes or to smaller classes with a structured format. Each of these classes then would have the same text, reading requirements, teaching methods, examinations, and content. 
2. We choos'e not to label research oriented students as superior and non-research students as less competent. Rather, we believe that continuing involvement in research studies beyond a minimum core program is a matter of individual preference or need. We recommend a specialized research segment of the curriculum, perhaps in collaboration with other behavioral sciences and an inter-disciplinary focus, encompassing techniques of research, statistical process, research concepts, analysis, computer technique and other more sophisticated technical procedures. This segment, perhaps interdisciplinary, but giving social work credit to social work students, could be included as an additional offering of the curriculum, available on an elective basis, for those students who may be research oriented, or who value extensive research in light of their career goals.

This specific research component of the curriculum could also offer seminars for graduates and agency persons involved in research activities related to individual agency problems and goals.

We have noted with interest that no comment regarding the research curriculum exists in the recommendations by the accreditation committee report of 1974. Since this study was considered a thorough and extensive overview of 
the whole social work curriculum, assumptions could be made that:

1. The present research component at the school of social work is satisfactory and meets the research requirement; or

2. Research activities were not considered in the accreditation committee procedures.

Although this study of the role of research in social work may provide some inference for structuring and refining the curriculum far social work students, we recognize the need for further studies utilizing a more detailed, sophisticated questionnaire which could be subjected to statistical processes.

We further recognize that our personal interpretation, understanding, and summarization of the individual comments of respondents is judgmental and, therefore, a limitation of the study. However, we feel that basic trends of thought do emerge through the repetition of comments and attitudes and that these responses do provide useful feedback.

Some of the variables associated with the responses in our study which should be recognized in further exploratory studies are: educational experience, work experience, level of proficiency, background information regarding each of the populations--faculty, student groups, agency personnal--as well as factors relating to types of agencies, career goals of students, needs of clients, the level of intensity in 
individual responses, and, realistically, the reliability of individual responses. Another consideration must be the atmost inevitable factor that student, faculty and agency responses will vary according to experience, area of interest, and level of professional responsibility of the respondent.

We found it interesting to note that students entering the school of social work in the fall of 1974 seemed to be more concerned with creditability and accountability, viewing research as necessary to justify agency programs, positions, and planning. We felt that this response could be a reflection upon either the local and/or the national economic situation or the lack of professional opporuntities in social work practice.

Many comments referred to "ethical performance, not politically tainted," "observation, not manipulation," which then may also relate to the national post Watergatè political climate in 1974-1975.

The following recommendations regarding the structure of a research program are based on student, faculty, and agency responses to our study.

1. We recommend that a core research experience be a part of each student's graduate education with a unified teaching approach to content and assignments.

2. We recommend that more advanced research experience be available based on (a) educational ob- 
jectives of the student's program; (b) the indi-. vidual student's learning needs, abilities and past experiences; (c) the administrative and faculty resources; and (d) the specific research experiences available at the school of social work. Perhaps the Portland State University Research facilities could be utilized to provide opportunities to involve more students in ongoing, funded studies. 


\section{. VII. A SELECTED BIBLIOGRAPHY}

Braden, William, The Age of Aquarius, Quadrangle Books, 1970, pp. $92-93$.

Chaiklin, Harris, "A Social Service Team for Public Welfare," Social Work Practice, Columbia University, N.Y. 1970, pp. 103-113.

Chaiklin, Harris, "Research and the Development of a Profession," Proceedings of Third Annual Conference, American Dance Therapy Association, Madison, Wisconsin, 1968, pp. 64-74.

Chaiklin, Harris, Associate Professor, University of Maryland School of Social Work and Planning, Baltimore, Maryland, Making Evaluation Useful.

Etzioni, Amitai, The Active Society, The Free Press, N.Y., 1968 , pp. $1 \overline{13-132}$.

Fellin, Phillips; Tony Tripodi, Henry T. Meyer, Exemplars of Sodial Research, 1969.

Ferman, Louis A., "Some Perspective on Evaluating Social Wel- fare Programs," The Annals, 385, September 1969, pp. 143-156.

Fishman, Joshua A., "Rejoinder," The Journal of Social Issues, October, 1968, pp. 182-185.

Flanagan, John C., "Evaluation of Research Data in Primary Prevention," American Journal of Orthopsychiatry, January, 1971, pp. 117-123.

Flexner, Abraham, I Remember, Simon \& Schuster, N.Y., 1940, pp. 113-132.

Hal1, George E. and Grey H. Lutz, An Evaluation of a Graduate Social Work Training Program at John Adams High School, Portland state University, $19 \overline{73}$.

Hirsch, Travis and Hannah C. Selvin, Delinquency Research, The Free Press, N.Y., 1967, pp. 145-146. 
Holles, Ernest and Alice I. Taylor, Social Work Education in the U.S., Columbia University Press, 1951.

Jennings, Daniel $\mathrm{F}$. and others, An Exploratory Study of Community Participation in the Governance of Schools of Social Work in the U.S., Portland State Universi$t_{y}$, June 1970 .

Kasịus, Cora, Ed. , New Directions in Social Work, Concepts and Methods in Social Work Research, 1954, chapter 12 .

Klein, Philip, The Contribution of Research to the Process of Social Work.

Making Evaluation Research Useful, a summary or proceedings of a workshop sponsored by the American City Corporation, 1971 .

Meier, Elizabeth G., A History of the New York School of Social Work, CoIumbia University Press, 1954 .

Mensh, I., Research in Counseling and Psychotherapy, D. Brower, I.Abt. , E ds., N.Y. 1956 , Vol. II.

Mikva, Abner, "The Politics of Legislation and the Welfare System," The People vs. The System, Social Tax, Acme Press, Inc., Chicago $\overline{19} 6 \overline{8,}$. 42 .

Morris, Robert, "Social Planning," Five Fields of Social Service, Reviews of Research, N.Y. 1966.

Morrison, Denton E. and Ramon E. Henkel, "Significance Tests Reconsidered," The American Sociologist, May 1969, pp. 131-140.

Parker, Edwin B., "Democracy and Information Processing," Educom 5, Fall 1970, pp. 2-6.

-Reiss, Albert J., Jr., "Putting Sociology into Policy," Social problems 17 (pros and cons of sociological involvement in policy research) Winter 1970, pp. 289-294.

Reynolds, Bertha Copen, Learning and Teaching in the Practice of Social Work, $19 \overline{42 .}$

Rodman, Hyman and Ralph I. Kolodny, "Organizational Strains in the Researcher-Practitioner Relationship," Applied Sociology: Opportunities and Problems, Alvin W. Gouldner and S. M. Miller, editors, 1965, pp. 93-114. 
Seltig, C., Responsive Methods in Social Relations, revised edition, Holt-Reinhart, N.Y. 1965.

Simon, Paul, Ji., Responsive Methods in Social Science, Random House, N.Y. 1969 .

Skogan, Leonard, The Relationships Among Social Work Practice, Social Work Research, and the Social Sciences, Chapter $5, \frac{\text { p. } 135}{\text {. }}$

Social Science Theory and Social Work Research, proceedings of an institute held by the Social Work Res Section of the WASW, June 8-1.2, 1959.

Suchman, Edward A., Evaluative Research, Russell Sage Foundation, N.Y. 1967 .

Tripodi, Tony, Uses and Abuses of Social Research, 1974.

Tufts, James H., Education and Training for Social Work, 1923.

U.S. Comptroller General, Report to the Congress Review of Economic Opportunity Programs, March 18, 19 $\overline{69, ~ p . ~} \overline{17} 7$.

Weinberger, Roslyn and Tony Tripodi, "Trends in Types of ReSearch Reported in Selected Social Work Journals,"

1956-65, Social Service Review, 43, December 1969, pp. $439-447$.

Williams, Walter and John W. Evans, "The Politics of Evaluation: The Case of Head Start," The Annals, 385, Sept. 1969 , pp. 118-132. 
APPENDIX A

QUESTIONNAIRE TO STUDENTS, FACULTY, FIELD INSTRUCTORS AND AGENCY DIRECTORS

Concerns have been expressed at Portland State University regarding research skills which may be necessary in a socilal work setting.

The purpose of this questionnaire is to determine needs for skills to be acquired in a research curriculum.

Total participation is necessary for this needs assessment. study.

PLEASE RETURN NO LATER THAN FRIDAY, FEBRUARY 8, 1974, TO JO IMESON, SCHOOI OF SOCIAL WORK, PSU.

THANK YOU FOR YOUR COOPERATION

Using your own personal experience, education, and/or professional judgment as criteria, please evaluate the following research skills:

In column $I$, check skills which you believe are necessary in a social work setting.

In column II, check skills which you believe social work students are being prepared adequately to use in a professional setting. 


\section{RESEARCH SKILIS}

1. Definition of a problem for social research.'

2. Formulation of realistic goals and objectives.

3. Utilization of methods of population measurement.

4. Development of relevant instruments for data collection.

5. Application of appropriate and scientific sampling techniques.

6. Analysis of data for a specific social work purpose.

7. Evaluation of a research project.

8. Evaluation of existing studies and application of results to ongoing work in program development.

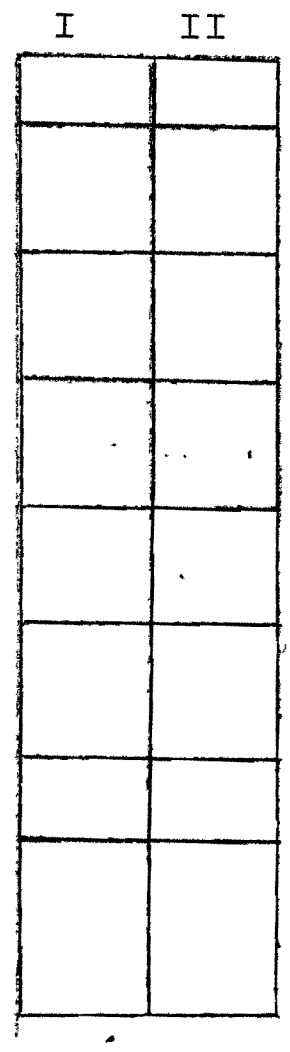

Are research skills necessary for all social work students?

Do you believe that social research seminars for agency personnel would be useful? 


\section{A.PPENDIX B}

$\underline{M} \underline{E} \underline{M} \underline{O}$

TO: First year students, PSU School of Social Work. FROM: Jo Imeson and Audrey Zalutsky SUBJECT: Questionnaire

We are constructing our thesis on "Research Skills in a Social Work Setting."

It will be helpful to us if you will answer the following questions and return your questionnaire to either Jo's or Audrey's mailbox.

We welcome your personal comments. Feel free to elaborate.

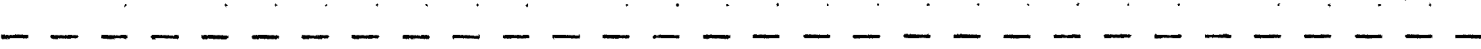

Do you believe that research skills are necessary for all social work students?

What are your attitudes, feelings, beliefs regarding research activities in a social agency? 